\title{
Handheld pH meter-assisted immunoassay for C-reactive protein using glucose oxidase-conjugated dendrimer loaded with platinum nanozymes
}

\author{
Bin $\mathrm{Li}^{1,2} \cdot$ Lilin $\mathrm{Ge}^{1} \cdot$ Peng $\mathrm{Lyu}^{3} \cdot$ Meijuan $\mathrm{Chen}^{4} \cdot$ Xiongfei Zhang ${ }^{4} \cdot$ Shuping $\mathrm{Xie}^{1,5} \cdot$ Qinan $\mathrm{Wu}^{1} \cdot \mathrm{Hang}$ Fai Kwok ${ }^{2}$
}

Received: 16 September 2020 / Accepted: 8 December 2020 / Published online: 3 January 2021

(C) The Author(s) 2021

\begin{abstract}
A simple and feasible $\mathrm{pH}$ meter-based immunoassay is reported for detection of C-reactive protein (CRP) using glucose oxidase (GOD)-conjugated dendrimer loaded with platinum nanozyme. Initially, platinum nanozymes were loaded into the dendrimers through an in situ synthetic method. Then, GOD and monoclonal anti-CRP antibody with a high molar ratio were covalently conjugated onto carboxylated dendrimers via typical carbodiimide coupling. The immunoreaction was carried out with a competitive mode in a CRP-coated microplate. Along with formation of immunocomplex, the added glucose was oxidized into gluconic acid and hydrogen peroxide by GOD, and the latter was further decomposed by platinum nanozyme, thus accelerating chemical reaction in the positive direction. The produced gluconic acid changed the $\mathrm{pH}$ of detection solution, which was determined using a handheld $\mathrm{pH}$ meter. Under optimum conditions, the $\mathrm{pH}$ meter-based immunoassay gave a good signal toward target CRP from 0.01 to $100 \mathrm{ng} \mathrm{mL}^{-1}$. The limit of detection was $5.9 \mathrm{pg} \mathrm{mL}^{-1}$. An intermediate precision $\leq 11.2 \%$ was acquired with batch-to-batch identification. No nonspecific adsorption was observed during a series of procedures to detect target CRP, and the cross-reaction against other biomarkers was very low. Importantly, our system gave well-matched results for analysis of human serum samples relative to a referenced ELISA kit.
\end{abstract}

Keywords Enzymatic cascade amplification · pH detection · Potentiometric immunoassay · Platinum nanozyme · Nanoparticle-encapsulated dendrimer $\cdot \mathrm{C}$-reactive protein

Bin Li and Lilin Ge contributed equally to this work.

Lilin Ge

gelilin@njucm.edu.cn

$\triangle$ Hang Fai Kwok

hfkwok@um.edu.mo

1 Collaborative Innovation Center of Chinese Medicinal Resources Industrialization, Nanjing University of Chinese Medicine, Nanjing 210023, People's Republic of China

2 Institute of Translational Medicine, Faculty of Health Sciences, University of Macau, Avenida de Universidade, Taipa, Macau SAR

3 College of Biological Science and Technology, Fuzhou University, Fuzhou 350108, Fujian, People's Republic of China

4 School of Medicine \& Holistic Integrative Medicine, Nanjing University of Chinese Medicine, Nanjing 210023, People's Republic of China

5 Division of Life Science, Hong Kong University of Science and Technology, Hong Kong, Hong Kong SAR

\section{Introduction}

C-reactive protein (CRP), a spherical pentameric protein called acute phase reactants, goes up in response to inflammation. It displays several functions associated with host defense to promote agglutination and bacterial capsular swelling, and complement fixation through its calcium-dependent binding to phosphorylcholine [1]. CRP can interact with DNA and histones, and it may scavenge nuclear material released from damaged circulating cells. The concentration of CRP in plasma increases greatly during acute phase response to tissue injuries, infections, cancers, and renal and cardiovascular diseases [2]. It is induced by interleukin-1 and interleukin-6. These proteins are produced by white blood cells during inflammation [3]. Therefore, sensitive and specific detection of CRP would be advantageous for protein diagnostics.

Nowadays, analytical methods for CRP mainly involve immunoassays and aptasensing protocols. Immunoassays, based on specific antigen-antibody reaction, have gained increasing attention and become the dominant test tools in 
clinical diagnostics for disease-related proteins $[4,5]$. $\mathrm{Wu}$ et al. developed a quantum dot-based immunoassay of CRP on a paper-based lateral flow test strip [6]. Broto et al. reported a nanoparticle-based bio-barcode assay for fluorescent detection of CRP in plasma samples [7]. Meyer et al. presented an immune-MALDI-MS approach for the quantification of CRP on reversed-phase tips [8]. Despite some advances in this field, there is still the requirement to simplify the assay procedures while preserving the essential benefits in sensitivity and specificity. In this regard, affordable medical diagnostics (i.e., point-of-care testing (POCT)) bring the patients for usage at bedside and the assays conveniently and immediately at the site of patient care $[9,10]$. The $\mathrm{pH}$ meter is currently one of the most widely used electric devices to measure hydrogenion activity (acidity or alkalinity) in solution, thanks to its portable size, low cost, easy operation, and reliable quantitative results $[11,12]$. Kwon et al. developed a pH meterbased immunoassay to detect the cardiac marker by using the labeled acetylcholinesterase with detection antibody for the hydrolysis of acetylcholine [11]. Chen et al. also constructed a pH meter-based potentiometric immunoassay by enzyme-conjugated hybridization chain reaction with two alternating hairpin DNA probes [13]. In these cases, the $\mathrm{pH}$ change of solution was derived from the labeled enzyme toward the catalysis/hydrolysis of substrates, and measured on a portable $\mathrm{pH}$ meter, thus reducing the difficulty of instrument operation $[14,15]$.

Another important issue for the development of the $\mathrm{pH}$ meter-based immunoassay with high efficiency is dependent on how to enhance sensitivity. Usually, diagnostic assay performance and practicality can be improved through engineering both the binding molecules and the reactions used to identify molecular binding events [16-19]. Dendrimers are well-defined and multivalent molecules with a highly branched three-dimensional nanometer-sized structure around an inner core with low polydispersity, and a high degree of functionality with abundant terminal groups [20]. Being a branched architecture, dendrimers have high surface to volume ratio [21]. Hydrophobic agents or inorganic nanoparticles can be easily loaded inside the cavity (void) in the dendrimer core [22, 23]. The presence of functional groups at the dendrimer surface provides the multivalent surface site for biomolecular conjugation via covalent/electrostatic interaction [24]. Typically, glucose oxidase (GOD) can oxidize glucose into gluconic acid and hydrogen peroxide [25]. Platinum nanoparticles (PtNPs) have been found to possess peroxidase-like activity [26, 27]. In the simultaneous presence of GOD and PtNPs, the added glucose molecules can convert into gluconic acid to maximum extent because PtNPs consume the produced hydrogen peroxide to push forward the oxidation reaction of glucose, thereby generating numerous gluconic acids. For this reason, our motivation in this study is to GOD- conjugate dendrimer loaded with PtNPs for the development of the $\mathrm{pH}$ meter-based immunoassay (Please see the detailed description on design of the $\mathrm{pH}$ meter-based immunosensing platform in the Supporting Information).

Herein, we design a simple and portable immunoassay for the sensitive detection of CRP with $\mathrm{pH}$ meter readout by GOD-conjugated dendrimer loaded with PtNPs (PtDENGOD) (Scheme 1). The immunoassay is implemented on CRP-coated microplates with a competitive reaction mode using anti-CRP antibody-labeled PtDEN-GOD as competitor. Subsequent $\mathrm{pH}$ detection of the as-produced gluconic acid in solution is conducted on a pH meter. The immunoassay combines high-loading dendrimer with GOD and platinum nanozyme for signal amplification. The objective of this work is to explore a new $\mathrm{pH}$ meter-assisted immunoassay for the cost-effective detection of low-abundance proteins with sensitivity enhancement.

\section{Materials and methods}

\section{Bioconjugation of carboxylated PtDEN with GOD and antibody (mAb-PtDEN-GOD)}

Before conjugation, PtNP-loaded bis-MPA-COOH dendrimer (denoted as PtDEN) was synthesized referring to previous report [28], and the detailed preparation process was described in the Supporting Information (note: bis-MPA-COOH $=2,2$ bis(hydroxymethyl)propionic acid). The generation 4 (G4) bis-MPA-COOH dendrimer (trimethylol propane core) was used as an example for the preparation of PtDEN because its surface was functionalized with 48 carboxyl groups to facilitate the conjugation of the subsequent antibodies. Next, GOD and monoclonal rabbit anti-human C-reactive protein antibody $(\mathrm{mAb})$ were conjugated to the PtDEN (denoted as mAb-PtDEN-GOD) through a typical carbodiimide coupling method [29]. Initially, NHS and EDC powders with an equal mass of $15 \mathrm{mg}$ were simultaneously thrown into the aboveprepared PtDEN suspension $(2.0 \mathrm{~mL})$, followed with continuous stirring ( $500 \mathrm{rpm}$ ) for $60 \mathrm{~min}$ at RT to activate the carboxyl groups on the surface of bis-MPA-COOH dendrimers. The resultant suspension was dialyzed using the abovementioned method ("Competitive immunoreaction and measurement on handheld $\mathrm{pH}$ meter") to remove excess EDC and NHS for avoiding the subsequent cross-linkage between proteins. Thereafter, $\mathrm{mAb}$ antibody $(0.5 \mathrm{~mL}, 200 \mu \mathrm{M})$ and GOD $(0.5 \mathrm{~mL}, 600 \mu \mathrm{M})$ were added into the mixture and incubated for $6 \mathrm{~h}$ at $4{ }^{\circ} \mathrm{C}$ under slight stirring. Following that, the suspension was centrifuged for $10 \mathrm{~min}$ at $5000 \mathrm{~g}$ to remove possibly produced precipitates during the reaction, and the collected supernatant was dialyzed as before. Finally, the obtained $\mathrm{mAb}-\mathrm{PtDEN}-\mathrm{GOD}$ was stored at $4{ }^{\circ} \mathrm{C}$ for further use. For comparison, other bioconjugates such as $\mathrm{mAb}$-conjugated 
Scheme 1 Schematic illustration of handheld $\mathrm{pH}$ meter-assisted immunoassay for detection of Creactive protein (CRP) by using glucose oxidase (GOD) and monoclonal rabbit anti-human $\mathrm{CRP}$ antibody (mAb)-conjugated bis-MPA-COOH dendrimer encapsulated with platinum nanozyme (PtDEN): (top) fabrication process of $\mathrm{mAb}$-PtDENGOD, and (bottom) competitive immunoreaction on CRP-coated microplate and enzymatic cascade reaction with $\mathrm{pH}$ meter readout

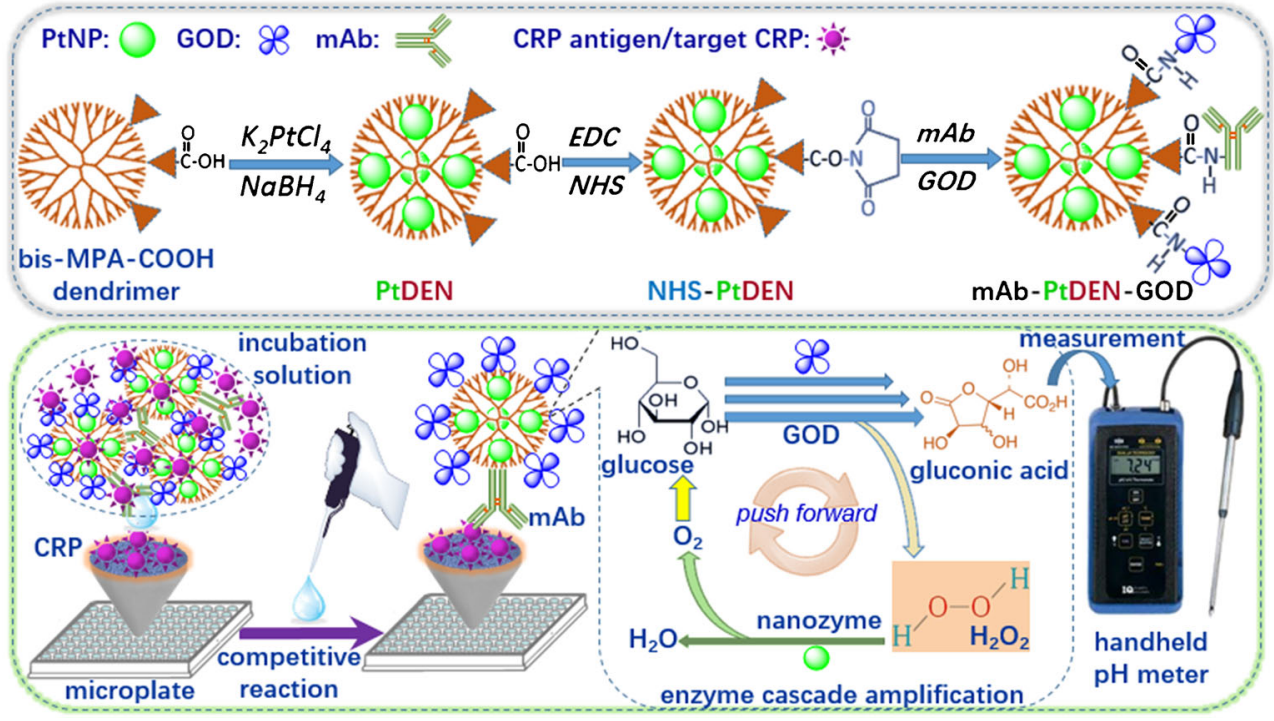

GOD (mAb-GOD), mAb-conjugated bis-MPA-COOH dendrimer (mAb-DEN), mAb and GOD-conjugated bis-MPA$\mathrm{COOH}$ dendrimer (mAb-DEN-GOD), and GOD-conjugated PtDEN (PtDEN-GOD) were prepared by using the similar method. PtNP-labeled mAb antibody (mAb-PtNP) and PtNP-labeled mAb/GOD (mAb-PtNP-GOD) were prepared by direct reaction of antibody or GOD with PtNP.

\section{Competitive immunoreaction and measurement on handheld pH meter}

Prior to measurement, CRP antigen-coated microplates were prepared as follows: (i) human C-reactive protein $(50 \mu \mathrm{L}$ per well, $10 \mu \mathrm{g} \mathrm{mL}^{-1}$ ) was added into a high-binding polystyrene 96-well microplate (cat\# 655061, Greiner, Frickenhausen, Germany) and incubated overnight at $4{ }^{\circ} \mathrm{C}$ with adhesive plastics plate sealing film; and (ii) the microplate was incubated again with $300 \mu \mathrm{L}$ per well of the blocking buffer (containing $1.0 \mathrm{wt} \% \mathrm{BSA}$ in $10 \mathrm{mM} \mathrm{pH} 7.4 \mathrm{PBS}$ ) for $60 \mathrm{~min}$ at RT with slight shaking on a shaker after washing three times with washing buffer (containing $0.05 \%$ Tween 20 , v/v, in $10 \mathrm{mM}$ $\mathrm{pH}$ 7.4 PBS). The plate was then washed as before. Following that, $50 \mu \mathrm{L}$ of CRP standard/sample and $50 \mu \mathrm{L}$ of the aboveprepared $\mathrm{mAb}$-PtDEN-GOD were added to the well in turn and incubated for $60 \mathrm{~min}$ at RT with slight shaking to execute the competitive immunoreaction. The plate was washed again. One hundred microliters of PBS (10 mM, pH 6.5) containing 2.0 $\mathrm{M}$ glucose was injected to the well and reacted for $8 \mathrm{~min}$ at RT for enzyme cascade reaction. Finally, $\mathrm{pH}$ of the resultant solution was measured on a handheld $\mathrm{pH}$ meter. The obtained $\mathrm{pH}$ value was registered as signal of the immunoassay relative to different-level target CRP. All the measurements were carried out at room temperature $\left(25 \pm 1.0{ }^{\circ} \mathrm{C}\right)$. All the data referred to the average response of reaction with the corresponding standard deviation (mean \pm SD) in triplicate, unless otherwise indicated. The sigmoidal curves were calculated by mathematically fitting experimental points using the Rodbard's four-parameter function with Origin 6.0 software. Graphs were plotted in the form of $\mathrm{pH}$ against the logarithm of CRP concentration.

\section{Results and discussion}

\section{Characterization of pH meter-based immunosensing platform}

For the development of the $\mathrm{pH}$ meter-based immunoassay, the successful preparation of CRP-coated microplate and mAb-PtDEN-GOD should be characterized in detail. Since the surface topological structure of CRP-coated microplate was difficultly characterized directly through scanning electron microscopy and atomic force microscopy, we herein employed high-resolution inverted microscopy to observe the topological change of the microplate before and after modification with CRP proteins. Figure 1a gives typical micrograph of high-binding polystyrene microplate with a very rough surface, which was favorable for physical adsorption of proteins. As shown in Fig. 1b, a large number of proteins were attached on the surface of microplate after incubation with CRP antigens (note: BSA blocking was not done in this micrograph), indicating successful fabrication of CRP-coated plate.

As mentioned above, PtNPs were in situ synthesized in the bis-MPA-COOH dendrimer. Figure 1c shows high-resolution transmission electron microscope (HRTEM) of the as-synthesized PtDENs. It is found that many PtNPs were distributed in the dendrimers, and the average size of nanoparticles was $2.3 \mathrm{~nm}$ in diameter. Moreover, we could also observe clearly the continuous lattice spacing of $0.226 \mathrm{~nm}$ corresponding to the 

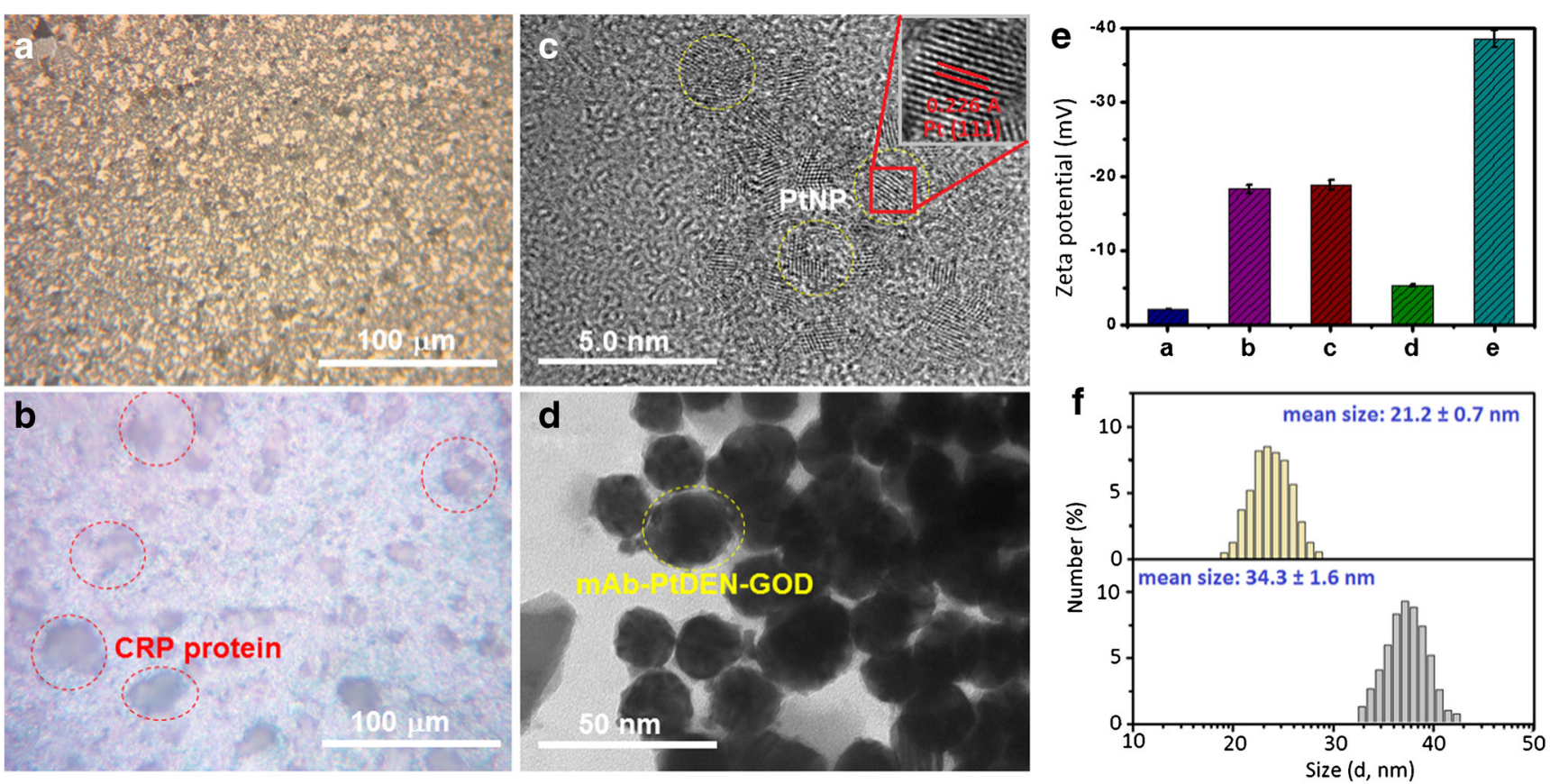

Fig. 1 High-resolution inverted microscope images of a unmodified microplate and b CRP-coated microplate. $\mathbf{c}$ HRTEM image of PtDEN. d TEM image of mAb-PtDEN-GOD after negative staining. E zeta

(111) facet of the face-centered cubic (fcc) platinum crystal [30, 31]. Also, X-ray photoelectron spectroscopy (XPS) measurement was performed for PtDENs. As expected, the characteristic peaks at $284.1 \mathrm{eV}, 530.1 \mathrm{eV}$, and $73.12 \mathrm{eV}$ related to $\mathrm{C} 1 \mathrm{~s}, \mathrm{O} 1 \mathrm{~s}$, and $\mathrm{Pt} 4 \mathrm{f}$ core level regions of PtDENs, respectively, were observed in Fig. S1A- $a$, indicating the presence of $\mathrm{Pt}$ nanoparticles in the dendrimer. Unfavorably, HRTEM image of PtDEN did not give the nanostructures of dendrimers since it was a kind of organic molecules, which could not be observed at the high voltage. To tackle this shortcoming, the as-prepared mAb-PtDENGOD conjugates were characterized by TEM after negative staining with sodium phosphotungstate $(2.0 \mathrm{wt} \%, \mathrm{pH} 7.3)$ (note: not good for negative staining of dendrimers). As seen from Fig. 1d, a layer of translucent structures was coated on the nearly spherical dendrimers, and the mean size was $\sim 28 \mathrm{~nm}$ in diameter. Logically, one puzzling question arises as to whether $\mathrm{mAb}$ antibodies and GOD molecules were really conjugated onto the dendrimers through the carbodiimide coupling. To demonstrate this issue, we used dynamic light scattering (DLS) to monitor zeta potentials and sizes of PtDEN after reaction with EDC/ NHS and $\mathrm{mAb}$ antibody, respectively (note: No obvious difference from characteristic peaks between PtDEN and mAb-PtDEN-GOD with Fourier transform infrared spectroscopy (FTIR) because they contained $\mathrm{C}=\mathrm{O}, \mathrm{N}-\mathrm{H}$, and $\mathrm{C}-\mathrm{N}$ bond, Fig. S1B). Pure PtNP $(\xi=-2.1 \mathrm{mV}$, Fig. 1ea) and bis-MPA-COOH dendrimer $(\xi=-18.3 \mathrm{mV}$, Fig. 1eb) exhibited a negatively charged species. In contrast, the zeta potentials of (a) PtNP, (b) bis-MPA-COOH dendrimer, (c) PtDEN, (d) EDC/NHS-activated PtDEN, and (e) mAb-PtDEN-GOD in ultrapure water. $\mathbf{f}$ DLS data of (top) PtDEN and (bottom) mAb-PtDEN-GOD

potential of the synthesized PtDEN $(\xi=-18.8 \mathrm{mV}$, Fig. 1ec) was slightly lower than that of bis-MPA-COOH dendrimer (Fig. 1 eb). When coupling carbodiimide of PtDEN with EDC/NHS, however, the potential increased to $5.4 \mathrm{mV}$ (Fig. 1ed), thanks to introduction of non-charged NHS molecules. Significantly, the zeta potential heavily decreased to $-38.5 \mathrm{mV}$ (Fig. 1 ee) after EDCfunctionalized PtDEN further reacted with GOD and $\mathrm{mAb}$ antibody. The reason was ascribed to the fact that the isoelectric points of GOD and anti-CRP antibody were pH 4.6 and $\sim \mathrm{pH} 5.7$ (which were measured by capillary isoelectric focusing electrophoresis, respectively), and they had negative charges in $\mathrm{pH} 7.0$ ultrapure water. Moreover, the size of mAb-PtDEN-GOD $(34.3 \pm 1.6 \mathrm{~nm})$ (Fig. 1f, bottom) was obviously more than that of PtDENs (21.2 \pm $0.7 \mathrm{~nm}$ ) (Fig. 1f, top) on the basis of DLS data (note: The sizes of PtDEN were almost the same before and after reaction with EDC/NHS, data not shown), and the increasing size mainly derived from the labeled biomolecules. Furthermore, another two characteristic peaks for N1s and $\mathrm{S} 2 \mathrm{p}$ for the proteins could be observed from the XPS data (Fig. S1A- $b$ ). These results preliminarily revealed the formation of mAb-PtDEN-GOD.

\section{Characteristics of the signal amplification and control tests}

By using the as-prepared mAb-PtDEN-GOD and CRP-coated microplate, we first evaluated the feasibility of the $\mathrm{pH}$ meter- 
based immunoassay for the detection of target CRP (1.0 ng mL $\mathrm{mL}^{-1}$ used as an example) with a competitive-type format. Figure 2a represents the background signal of $\mathrm{pH} 6.5 \mathrm{PBS}$. Obviously, the presence of target CRP could cause the $\mathrm{pH}$ change of the detection solution (Fig. 2c) in comparison with zero analyte (Fig. 2b). The $\mathrm{pH}$ shift in the presence of target CRP was ascribed to the competitive immunoreaction between target CRP and the coated CRP on the microplate for the labeled $\mathrm{mAb}$ on mAb-PtDEN-GOD, thus decreasing the captured amount of mAb-PtDEN-GOD on the microplate. These results indicated that the $\mathrm{pH}$ meter-based immunoassay was feasible for the detection of target CRP on CRP-coated microplate by using $\mathrm{mAb}-\mathrm{PtDEN}-\mathrm{GOD}$ as the signal tag.

As described above, the as-synthesized mAb-PtDEN-GOD had the cascade signal amplification. To clarify this issue, a comparative study was carried out by using differently labeled probes (i.e., mAb-DEN, mAb-DEN-GOD, and mAb-PtDENGOD) for the detection of $1.0 \mathrm{ng} \mathrm{mL}^{-1} \mathrm{CRP}$ on CRP-coated microplate. The immunoassay of using mAb-DEN (Fig. 2d) gave almost the same $\mathrm{pH}$ signal as that of $\mathrm{pH} 6.5$ PBS (Fig. $2 a$ ), indicating that the formed immunocomplex with mAb-DEN could not change the $\mathrm{pH}$ of detection solution. Significantly, $\mathrm{pH}$ of detection solution gradually decreased when using mAbDEN-GOD (Fig. 2e) and mAb-PtDEN-GOD (Fig. 2f) as the signal tags. The reason was ascribed to the fact that the added glucose molecules were first oxidized to gluconic acid and hydrogen peroxide $\left(\mathrm{H}_{2} \mathrm{O}_{2}\right)$ by the conjugated GOD in the presence of oxygen, and then, the produced $\mathrm{H}_{2} \mathrm{O}_{2}$ was reduced to hydrogen oxide $\left(\mathrm{H}_{2} \mathrm{O}\right)$ and oxygen $\left(\mathrm{O}_{2}\right)$ via platinum nanozyme with peroxidase-like activity, thus pushing glucose oxidation forward to generate numerous gluconic acid molecules with the signal amplification (Please see the detailed discussion on the role of platinum nanoparticles, glucose oxidation reaction process with
GOD and PtNP, and comparative studies of differently labeled probes for the signal amplification in the Supporting Information, Fig. S2-S5).

Except for the cascade signal amplification by GOD and the encapsulated PtNP in the dendrimer, we also monitored the advantages of bis-MPA-COOH dendrimers by comparing with four labeled probes: $\mathrm{mAb}-\mathrm{GOD}$, mAb-DEN-GOD, mAb-PtNPGOD, and mAb-PtDEN-GOD. It is found that $\mathrm{pH}$ variations (relative to pH 6.5 PBS, Fig. 2a) of using mAb-DEN-GOD (Fig. 2h) and mAb-PtDEN-GOD (Fig. 2j) were more than those of mAb-GOD (Fig. 2(g)) and mAb-PtNP-GOD (Fig. 2i), suggesting that introduction of the dendrimers could amplify the detectable signal (Please see the detailed discussion on the role of dendrimer in the Supporting Information, Fig. S6). As the control tests, PtDEN-GOD (Fig. 2k), mAb-PtNP (Fig. 2m), and $\mathrm{mAb}$ (Fig. 2n) were employed as the signal tags for detection of $1.0 \mathrm{ng} \mathrm{mL}^{-1} \mathrm{CRP}$ on CRP-coated microplate, respectively. Almost no $\mathrm{pH}$ variations were observed in these cases relative to $\mathrm{pH} 6.5$ background signal (Fig. 2a). Furthermore, we also found that the cascade reaction could not be fulfilled in the absence of GOD, even if platinum nanozyme was labeled to mAb antibody (Fig. 2m). On the basis of these results, we could clearly confirm that the synthesized mAb-PtDEN-GOD could be utilized as the signal tag to amplify the signal of the $\mathrm{pH}$ meter-based immunoassay.

\section{Calibration plots of pH meter-based immunoassay toward target CRP standards}

Under the optimum conditions (Please see the relative description in the Supporting Information, Fig. S7), CRPcoated microplate and mAb-PtDEN-GOD were utilized to determine CRP standards with different concentrations on a

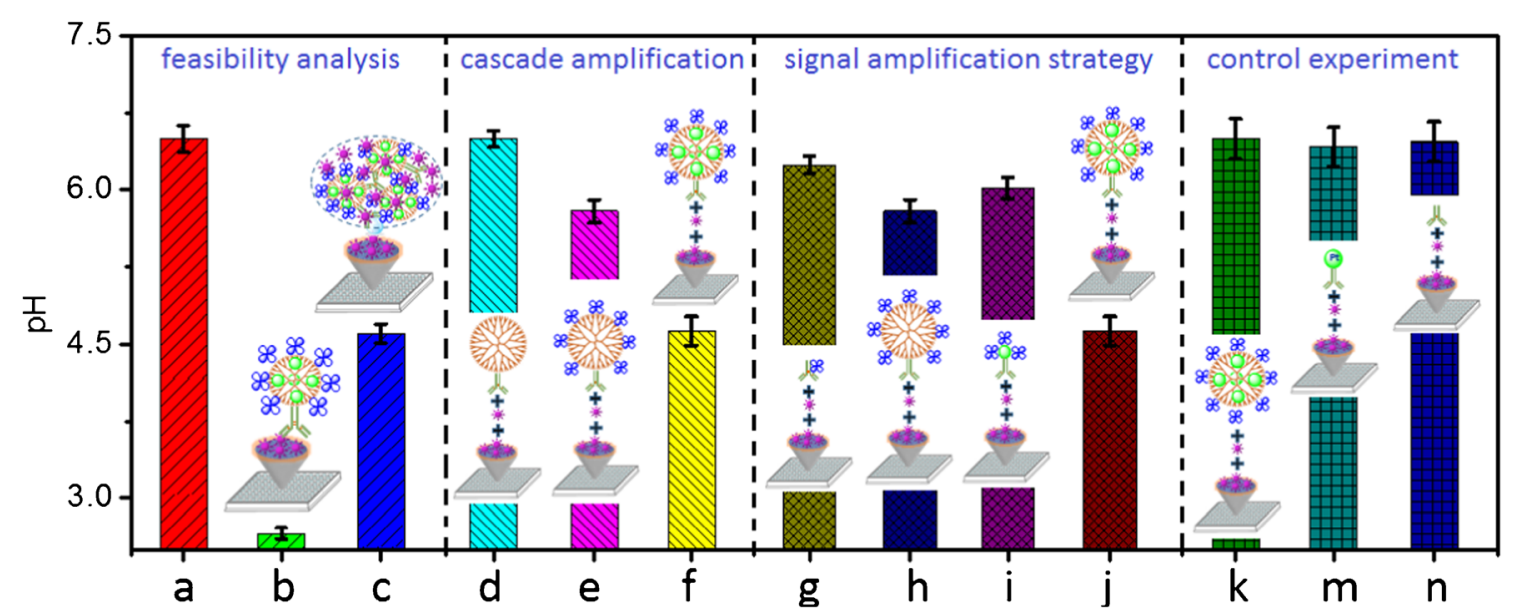

Fig. 2 Signal readouts of a pH 6.5 PBS (10 mM), and (b, c) pH meterbased immunoassay in the absence (b) and presence $\mathbf{c}$ of $1.0 \mathrm{ng} \mathrm{mL}$ CRP with mAb-PtDEN-GOD. (d-n) Signal readouts of $\mathrm{pH}$ meter-based immunoassay in the presence of $1.0 \mathrm{ng} \mathrm{mL}^{-1} \mathrm{CRP}$ using differently labeled probes: $\mathbf{d} \mathrm{mAb}-\mathrm{DEN}$; e mAb-DEN-GOD; (f, j) mAb-PtDENGOD; $\mathbf{g}$ mAb-GOD; h mAb-DEN-GOD; i mAb-PtNP-GOD; k PtDEN-

GOD; $\mathbf{m}$ mAb-PtNP; and $\mathbf{n}$ mAb. All immunoreactions were carried out on CRP-coated microplates, and the final $\mathrm{pH}$ measurement was executed in PBS $(100 \mu \mathrm{L}, 10 \mathrm{mM}, \mathrm{pH}$ 6.5) containing $2.0 \mathrm{M}$ glucose. Each data point represents the average value obtained from three measurements, and the error bars stand for $95 \%$ confidence interval of the mean for $\mathrm{pH}$ value 
handheld $\mathrm{pH}$ meter with a competitive immunoassay mode. Figure 3a shows $\mathrm{pH}$ variations of the $\mathrm{pH}$ meter-based immunoassay relative to the decimal logarithm of CRP concentrations within the dynamic range of $0.001-1000 \mathrm{ng} \mathrm{mL}^{-1}$. Obviously, $\mathrm{pH}$ variations were very small at high and low levels of $100-1000 \mathrm{ng} \mathrm{mL}^{-1}$ and $0.001-0.01 \mathrm{ng} \mathrm{mL}^{-1}$. A good linear relationship was acquired in the concentration range from 0.01 to $100 \mathrm{ng} \mathrm{mL}^{-1}$ with a detection limit (LOD) of $5.9 \mathrm{pg} \mathrm{mL}^{-1}$ and a limit of quantification (LOQ) of $19.7 \mathrm{pg} \mathrm{mL}^{-1}$ at signal-to-noise ratios of $3 \sigma$ and $10 \sigma$, respectively (where $\sigma$ is the standard deviation of a blank solution, $n=11)$. The regression equation could be fit as $y(\Delta \mathrm{pH})=$ $1.87+0.99 \times \log C_{\text {[CRP] }}\left(\mathrm{ng} \mathrm{mL}^{-1}, r=0.9928, n=8\right)$. The sensitivity of the $\mathrm{pH}$ meter-based immunoassay was $9.77 \mathrm{pH} \mathrm{ng} /$ $\mathrm{mL}$. Moreover, the linear range and limit of detection of the $\mathrm{pH}$ meter-based immunoassay were comparable with those of other CRP assay methods (Table 1). Though the LOD of our strategy was higher than those of partial electrochemical systems, the developed $\mathrm{pH}$ meter-based immunoassay did not need expensive instrumentations, and professional/technical personnel. Significantly, our system was capable of continuously performed all steps within $\leq 70 \mathrm{~min}$ for one sample, including incubation, washing and $\mathrm{pH}$ measurement, which was less than for commercial CRP ELISA kit (approximately $3.5 \mathrm{~h}$ ). Meanwhile, the $\mathrm{pH}$ meter-based immunoassay was relatively simple and low-cost without the expensive instruments and complex operation ( $\sim$ USD $\$ 1.93$ for a single test versus $\sim$ USD \$7.81 per sample with commercialized available human CRP ELISA kit from Sigma-Aldrich Product cat\# no.: RAB0096).

\section{Reproducibility, specificity, and storage stability}

To investigate the reproducibility of the $\mathrm{pH}$ meter-based immunoassays, CRP-coated microplate and mAb-PtDEN-GOD with the same batch or different batches were used for the determination of three CRP levels (i.e., 0.01, 1.0, and $100 \mathrm{ng} \mathrm{mL} \mathrm{m}^{-1}$ used in this case) because the immunoassay could not be repeatedly used (disposable). The coefficients of variation $(\mathrm{CVs})$ for the intra-assays were $5.8 \%, 3.4 \%$, and $7.1 \%(n=3)$ for $0.01,1.0$, and $100 \mathrm{ng} \mathrm{mL}^{-1}$, respectively, whereas those for the inter-assays were $10.4 \%, 9.8 \%$, and $11.2 \%(n=3)$ for the abovementioned levels. Hence, the reproducibility and precision of the $\mathrm{pH}$ meter-based immunoassays were acceptable.

The specificity of the $\mathrm{pH}$ meter-based immunoassay was studied by analyzing other proteins or biomarkers possibly present in human serum, e.g., neuron-specific enolase (NSE), alpha-fetoprotein (AFP), carcinoembryonic antigen (CEA), squamous cell carcinoma antigen (SCCA), calcitonin (CT), tissue polypeptide antigen (TPA), BSA, and IgG. The evaluation was carried out by assaying the non-targets alone or mixture containing CRP and non-target. The comparison was performed by observing the effect of high-concentration non-targets on the low-level CRP. As shown in Fig. 3b, pH variations of non-targets were close to zero, and strong $\mathrm{pH}$ variations could be observed in the presence of CRP. Compared with pure CRP alone, introduction of non-targets with target CRP did not cause the significant $\mathrm{pH}$ variations, thus suggesting high selectivity and specificity.

The storage stability of CRP-coated microplates and $\mathrm{mAb}$ PtDEN-GOD were monitored over a 1 -year period at $4{ }^{\circ} \mathrm{C}$. After every 1 month, they were taken out to measure target CRP (1.0 $\mathrm{ng} \mathrm{mL}^{-1}$ used as an example). As seen from Fig. 3c, $\mathrm{pH}$ variations could maintain $\geq 95 \%$ of the initial signal within 8 months. After storing for 11 months, the signal could also preserve more than $90 \%$. Such long-term storage stability mainly stemmed from covalent conjugation of $\mathrm{mAb}$ and GOD with PtDEN and high-binding polystyrene microplate.

\section{Analysis of human serum specimens}

To investigate the accuracy of the $\mathrm{pH}$ meter-based immunoassay, we collected 20 human serum specimens containing target CRP from the hospital of our University. All the
Table 1 Comparison of $\mathrm{pH}$ meter-based immunoassay with other CRP detection methods on analytical properties

\begin{tabular}{llll}
\hline Method & Linear range & LOD & Ref. \\
\hline Colorimetric aptamer assay & $0.889-20.7 \mu \mathrm{g} \mathrm{mL}^{-1}$ & $1.2 \mu \mathrm{g} \mathrm{mL}^{-1}$ & {$[32]$} \\
Biophotonic assay & $2.0-14.7 \mu \mathrm{g} \mathrm{m}^{-1}$ & $0.42 \mu \mathrm{g} \mathrm{mL}^{-1}$ & {$[33]$} \\
Electrochemical immunosensor & $0.01-100 \mathrm{ng} \mathrm{mL}^{-1}$ & $3.3 \mathrm{pg} \mathrm{mL}^{-1}$ & {$[34]$} \\
Capacitive immunoassay & $0.25-2.0 \mu \mathrm{g} \mathrm{mL}^{-1}$ & $0.5 \mu \mathrm{gL} \mathrm{m}^{-1}$ & {$[35]$} \\
Impedimetric immunoassay & $0.2-5.0 \mu \mathrm{g} \mathrm{mL}^{-1}$ & $3.7 \mathrm{pg} \mathrm{mL}^{-1}$ & {$[36]$} \\
Electrochemiluminescence immunosensor & $0.05-6.25 \mathrm{ng} \mathrm{mL}^{-1}$ & $11 \mathrm{pg} \mathrm{mL}^{-1}$ & {$[37]$} \\
Impedimetric immunosensor & $0.1-10 \mathrm{ng} \mathrm{mL}^{-1}$ & $0.1 \mathrm{ng} \mathrm{mL}^{-1}$ & {$[38]$} \\
Fluorescent immunodipsticks & $0.5-1000 \mathrm{ng} \mathrm{mL}^{-1}$ & $0.3 \mathrm{ng} \mathrm{mL}^{-1}$ & {$[6]$} \\
Electrochemical immunoassay & $0.05-100 \mu \mathrm{g} \mathrm{mL}^{-1}$ & $15 \mathrm{ng} \mathrm{mL}^{-1}$ & {$[39]$} \\
pH meter-based immunoassay & $0.01-100 \mathrm{ng} \mathrm{mL}^{-1}$ & $5.9 \mathrm{pg} \mathrm{mL}^{-1}$ & This work \\
\hline
\end{tabular}



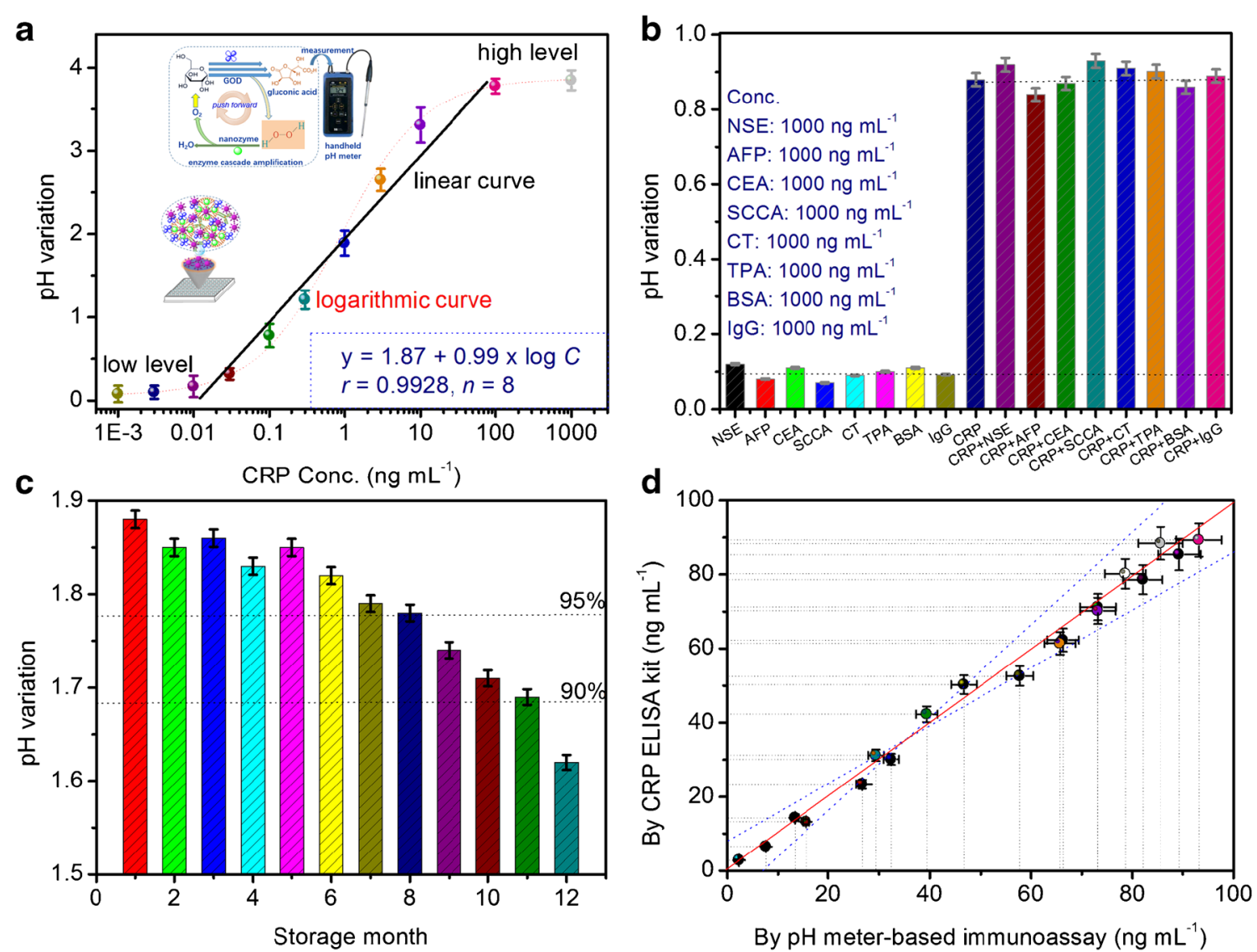

Fig. 3 a Calibration plots of $\mathrm{pH}$ meter-based immunoassay toward different-concentration CRP standards with a competitive-type assay format by using mAb-PtDEN-GOD as the competitor in PBS $(100 \mu \mathrm{L}$, $10 \mathrm{mM}, \mathrm{pH} 6.5$ ) containing $2.0 \mathrm{M}$ glucose. b The specificity of $\mathrm{pH}$ meter-based immunoassay against $0.1 \mathrm{ng} \mathrm{mL}^{-1} \mathrm{CRP}, 1000 \mathrm{ng} \mathrm{mL}^{-1}$ NSE, $1000 \mathrm{ng} \mathrm{mL}^{-1} \mathrm{AFP}, 1000 \mathrm{ng} \mathrm{mL}^{-1} \mathrm{CEA}, 1000 \mathrm{ng} \mathrm{mL}^{-1}$ SCCA, $1000 \mathrm{ng} \mathrm{mL}^{-1} \mathrm{CT}, 1000 \mathrm{ng} \mathrm{mL}^{-1} \mathrm{TPA}, 1000 \mathrm{ng} \mathrm{mL}^{-1} \mathrm{BSA}$, and

experiments were performed in compliance with the relevant laws and Guidelines of Nanjing University of Chinese Medicine (China), and the experiments have been approved. Informed consent was obtained for any experimentation with human subjects. Prior to measurement, these serum samples were initially centrifuged for $10 \mathrm{~min}$ at $5000 \mathrm{~g}$ to remove the possible precipitates, and then were determined by using the $\mathrm{pH}$ meter-based immunoassay. As the reference, the obtained results were compared with those of using commercial CRP ELISA kits (Fig. 3d). As shown in Fig. 3d, the data from two methods were fit to a regression equation as follows: $y=0.0698+0.9733 x(r=$ $0.9917, n=20$ ). The slope and intercept of the regression equation were close to ideal " 0 " and " 1, " respectively [ 40 , 41]. Therefore, almost no significant differences at the 0.05 significance level were encountered for the analysis of 20 human serum specimens between two methods, indicating good accuracy.

$1000 \mathrm{ng} \mathrm{mL}^{-1}$ IgG. c The storage stability of CRP-coated microplate and $\mathrm{mAb}$-PtDEN-GOD. $\mathbf{d}$ Method accuracy for analysis of human serum specimens between $\mathrm{pH}$ meter-based immunoassay and commercial CRP ELISA kit. Each data point represents the average value obtained from three measurements $(n=3)$, and the error bars stand for the 95\% confidence interval of the mean for $\mathrm{pH}$ variation

\section{Conclusions}

This study successfully developed a simple and easyoperation immunoassay for the quantitative screening of Creactive protein on a handheld $\mathrm{pH}$ meter. Experimental results indicated that the $\mathrm{pH}$ meter-based immunoassay had high sensitivity, good reproducibility, high specificity, and longterm storage stability. Combination of natural enzyme with nanozyme can efficiently promote the adequate catalysis of the substrates, thus facilitating the formation of the products. Moreover, one-step immunoreaction with one-kind antibody reduces the assay time and decrease the assay cost. Furthermore, the $\mathrm{pH}$ meter-based immunoassay with the coated microplates can be used in the miniaturized devices by using the portable $\mathrm{pH}$ meters, thus opening new opportunities for the protein diagnostics and biosecurity. Nevertheless, one disadvantage of our strategy is that the incubation time for target CRP is relatively long during the competitive 
immunoreaction. Therefore, future work should focus on improvement of reaction systems or reactive conditions.

Supplementary Information The online version contains supplementary material available at https://doi.org/10.1007/s00604-020-04687-9.

Funding This work is supported by the National Natural Science Foundation of China (grant no.: 81703750) and the Science and Technology Development Fund, Macau SAR (file no.: 0055/2019/A1).

\section{Compliance with ethical standards}

Conflict of interest The authors declare that they have no competing interests.

Ethical approval All experiments were performed in compliance with the relevant laws and Guidelines of Nanjing University of Chinese Medicine (China), and the experiments have been approved.

Informed consent Informed consent was obtained from all individual participants included in the studySupplementary Information The online version contains supplementary material available at https://doi.org/10.1007/s00604-020-04687-9.

Open Access This article is licensed under a Creative Commons Attribution 4.0 International License, which permits use, sharing, adaptation, distribution and reproduction in any medium or format, as long as you give appropriate credit to the original author(s) and the source, provide a link to the Creative Commons licence, and indicate if changes were made. The images or other third party material in this article are included in the article's Creative Commons licence, unless indicated otherwise in a credit line to the material. If material is not included in the article's Creative Commons licence and your intended use is not permitted by statutory regulation or exceeds the permitted use, you will need to obtain permission directly from the copyright holder. To view a copy of this licence, visit http://creativecommons.org/licenses/by/4.0/.

\section{References}

1. Azam A, Fatemeh R, Fatemeh A (2020) Role of C-reactive protein CRP. or high-sensitivity CRP in predicting gestational diabetes mellitus: systematic review. Diabetes \& Metabolic Syndrome 14: 229-236

2. Brow J, Meader N, Wright K, Cleminson J, McGuire W (2020) Assessment of C-reactive protein diagnostic test accuracy for lateonset infection in newborn infants: a systematic review and metaanalysis. JAMA Pediatr 174:260-268

3. Lambertsen K, Soares C, Gaist D, Nielsen H (2020) Neurofilaments: the C-reactive protein of neurology. Brain Sci 10:56

4. Shu J, Tang D (2020) Recent advances in photoelectrochemical sensing: from engineered photoactive materials to sensing devices and detection modes. Anal Chem 92:363-377

5. Huang L, Chen J, Yu Z, Tang D (2020) Self-powered temperature sensor with Seeback effect transduction for photothermalthermoelectric coupled immunoassay. Anal Chem 92:2809-2814
6. Wu R, Zhou S, Chen T, Li J, Shen H, Chai Y, Li L (2018) Quantitative and rapid detection of C-reactive protein using quantum dot-based lateral flow test strip. Anal Chim Acta 1008:1-7

7. Broto M, Galve R, Marco M (2017) Sandwich NP-based biobarcode assay for quantification $\mathrm{C}$-reactive protein in plasmon samples. Anal Chim Acta 992:112-118

8. Meyer K, Ueland P (2014) Targeted quantification of C-reactive protein and cystatin $\mathrm{C}$ and its variants by immune-MALDI-MS. Anal Chem 86:5807-5814

9. Ge L, Li B, Xu H, Pu W, Kwok H (2019) Backfilling rolling cycle amplification with enzyme-DNA conjugates on antibody for portable electrochemical immunoassay with glucometer readout. Biosens Bioelectron 132:210-216

10. Chen L, Wang E, Tai C, Chiu Y, Li C, Lin Y, Lee T, Huang C, Chen J, Chen W (2020) Improving the reproducibility, accuracy, and stability of an electrochemical biosensor platform for point-ofcare use. Biosens Bioelectron 155:112111

11. Kwon D, Joo J, Lee S, Jeon S (2013) Facile and sensitive method for detecting cardiac markers using ubiquitous $\mathrm{pH}$ meters. Anal Chem 85:12134-12137

12. Wang J, Song M, Hu C, Wu K (2018) Portable, self-powdered, and light-addressable photoelectrochemical sensing platforms using $\mathrm{pH}$ meter readouts for high-throughput screening of thrombin inhibitor drugs. Anal Chem 90:9366-9373

13. Chen J, Xue H, Chen Q, Lin Y, Tang D, Zheng J (2019) Enzymeconjugated hybridization chain reaction for magneto-controlled immunoassay of squamous cell carcinoma antigen with $\mathrm{pH}$ meter. Chin Chem Lett 30:1631-1634

14. Zhang Y, Yang J, Nie J, Yang J, Gao D, Zhang L, Li J (2016) Enhanced ELISA using a handheld $\mathrm{pH}$ meter and enzyme-coated microparticles for the portable, sensitive detection of proteins. Chem Commun 52:3474-3477

15. Ye R, Zhu C, Song Y, Lu Q, Ge X, Yang X, Zhu M, Du D, Li H, Lin Y (2016) Bioinspired synthesis of all-in-one organic-inorganic hybrid nanoflowers combined with a handheld $\mathrm{pH}$ meter for on-site detection of food pathogen. Small 12:3094-3100

16. Xie S, Li B, Lyu P, Kwok H, Ge L, Wu Q (2020) A new voltammetric immunosensing platform for prostate-specific antigen based on the $\mathrm{Cu}(\mathrm{II})$-pyrophosphate ion chelation reaction. New J Chem 44:3820-3823

17. Sun A, Qi Q, Zhi L (2020) Cross-linkage urease nanoparticles: a high-efficiency signal-generation tag for portable $\mathrm{pH}$ meter-based electrochemical immunoassay of lipocalin-2 protein diagnostics. Microchim Acta 187:485

18. Jiang Y, Su Z, Zhang J, Cai M, Wu L (2018) A novel electrochemical immunoassay for carcinoembryonic antigen based on glucose oxidase-encapsulated nanogold hollow spheres with a $\mathrm{pH}$ meter readout. Analyst 143:5271-5277

19. Qiu Z, Shu J, Tang D (2017) Bioresponsive release system for visual fluorescence detection of carcinoembryonic antigen for mesoporous silica nanocontainers mediated optical color on quantum dot-enzyme-impregnated paper. Anal Chem 89:5152-5160

20. Ren L, Lv J, Wang H, Cheng Y (2020) A coordinative dendrimer achieves excellent efficiency in cytosolic protein and peptide delivery. Angew Chem Int Ed 59:4711-4719

21. Wang C, Zhao X, Liu F, Chen Y, Xia X, Li J (2020) Dendrimer-Au nanoparticle network covered alumina membrane for ion rectification and enhanced bioanalysis. Nano Lett 20:1846-1854

22. Zhu Y, Liu C, Pang Z (2019) Dendrimer-based drug delivery systems for brain targeting. Biomolecules 9:790

23. Elbert K, Vo T, Krook N, Zygmunt W, Park J, Yager K, Composto R, Glotzer S, Murray C (2019) Dendrimer ligand directed nanoplate assembly. ACS Nano 13:14241-14251

24. Lee C, Ju Y, Shim S, Kim J, Kim T (2019) Single-walled carbon nanotubes decorated with dendrimer-enhanced platinum 
nanoparticles as catalytic immobilization matrix for amperometric sensing of glutamate. J Biomed Nantotechnol 15:2321-2331

25. Ren R, Cai G, Yu Z, Tang D (2018) Glucose-loaded liposomes for amplified colorimetric immunoassay of streptomycin based on enzyme-induced iron(II) chelation reaction with phenanthroline. Sensors Actuators B Chem 265:174-1818

26. Yu Z, Tang Y, Cai G, Ren R, Tang D (2019) Paper electrode-based flexible pressure sensor for point-of-care immunoassay with digital multimeter. Anal Chem 91:1222-1126

27. Zeng R, Luo Z, Zhang L, Tang D (2018) Platinum nanozymecatalyzed gas generation for pressure-based bioassay using polyaniline nanowires-functionalized graphene oxide framework. Anal Chem 90:1229-12306

28. Lang H, May R, Iversen B, Chandler B (2003) Dendrimerencapsulated nanoparticle precursors to supported platinum catalysts. J Am Chem Soc 125:14832-14836

29. Hou L, Cui Y, Xu M, Gao Z, Huang J, Tang D (2013) Graphene oxide-labeled sandwich-type impedimetric immunoassay with sensitive enhancement based on enzymatic 4-chloro-1-naphthol oxidation. Biosens Bioelectron 47:149-156

30. Wu G, He S, Peng H, Deng H, Liu A, Lin X, Xia X, Chen W (2014) Citrate-capped platinum nanoparticle as a smart probe for ultrasensitive mercury sensing. Anal Chem 86:10955-10960

31. Zhang K, Dong H, Dai W, Meng X, Lu H, Wu T, Zhang X (2017) Fabricating Pt $/ \mathrm{Sn}-\mathrm{In}_{2} \mathrm{O}_{3}$ nanoflower with advanced oxygen reduction reaction performance for high-sensitivity microRNA electrochemical detection. Anal Chem 89:648-655

32. Antonio M, Ferreira R, Vitorina R, Daniel-da-Silva A (2020) A simple aptamer-based colorimetric assay for rapid detection of Creactive protein using gold nanoparticles. Talanta 214:120868

33. James-Pemberton P, Lapinska U, Helliwell M, Olkhov R, Hedaux O, Hyde C, Shaw A (2020) Accuracy and precision analysis of a biophotonic assay of C-reactive protein. Analyst 145:2751-2757
34. Ma Y, Yang J, Yang T, Deng Y, Gu M, Wang M, Hu R, Yang Y (2020) Electrochemical detection of C-reactive protein using functionalized iridium nanoparticles/graphene oxide as a tag. RSC Adv 10:9732-9729

35. Baradoke A, Hein R, Li X, Davis J (2020) Reagentless redox capacitive assaying of $\mathrm{C}$-reactive protein at a polyaniline interface. Anal Chem 92:3508-3511

36. Kanong P, Davis J (2020) Homogeneous functional self-assembled monolayers: faradaic impedance baseline signal drift suppression for high-sensitivity immunosensing of C-reactive protein. J Electroanal Chem 856:113675

37. Rong Z, Chen F, Jilin Y, Tu Y (2019) A C-reactive protein immunosensor based on platinum nanowire/titania nanotube composite sensitized electrochemiluminescence. Talanta 205:120135

38. Tanak A, Jagannath B, Tamrakar Y, Muthukumar S, Prasad S (2019) Non-faradaic electrochemical impedimetric profiling of procalcitonin and $\mathrm{C}$-reactive protein as a dual marker biosensor for early sepsis detection. Anal Chim Acta X 3:100029

39. Boonkaew S, Chaiyo S, Jampasa S, Rengpipat S, Siangproh W, Chailapakul O (2019) An origami paper-based electrochemical immunoassay for the $\mathrm{C}$-reactive protein using a screen-printed carbon electrode modified with graphene and gold nanoparticles. Microchim Acta 186:153

40. Lv S, Zhang K, Zhu L, Tang D (2020) ZIF-8-assisted NaYF4:Yb, Tm@ZnO converter with exonuclease III-powered DNA walker for near-infrared light responsive biosensor. Anal Chem 92:1470 1476

41. Zeng R, Luo Z, Su L, Zhang L, Tang D, Niessner R, Knopp D (2019) Palindromic molecular beacon based Z-scheme BiOCl-AuCdS photoelectrochemical biodetection. Anal Chem 91:2447-2454

Publisher's note Springer Nature remains neutral with regard to jurisdictional claims in published maps and institutional affiliations. 